\title{
Inequalities in the distribution of dental caries among 12-year-old Brazilian schoolchildren
}

\section{Chaiana Piovesan ${ }^{(a)}$ Fausto Medeiros Mendes ${ }^{(b)}$ José Leopoldo Ferreira Antunes(a) Thiago Machado Ardenghi ${ }^{(c)}$}

(a) Department of Orthodontics and Pediatric Dentistry, School of Dentistry, University of São Paulo, São Paulo, SP, Brazil.

(b) Department of Epidemiology, School of Public Health, University of São Paulo, São Paulo, SP, Brazil.

(c) Department of Stomatology, Federal University of Santa Maria, Santa Maria, RS, Brazil.
Corresponding author:

Chaiana Piovesan

Rua José Alves Cunha Lima, 159,

apto. 7034, Butantã

São Paulo - SP - Brazil

CEP: 05360-050

E-mail: chaiana@usp.br

Received for publication on Jul 23, 2010 Accepted for publication on Oct 23, 2010

\begin{abstract}
We assessed the inequality in the distribution of dental caries and the association between indicators of socioeconomic status and caries experience in a representative sample of schoolchildren. This study followed a cross-sectional design, with a sample of 792 schoolchildren aged 12 years, representative of this age group in Santa Maria, RS, Brazil. Guardians answered questions on socioeconomic status and a dental examination provided information on the dental caries experience (DMF-T). Inequality in dental caries distribution was measured by the Gini coefficient and the Significant Caries Index (SiC). The assessment of association used Poisson regression models. Socioeconomic factors were associated with prevalence of dental caries for the whole sample and also for individuals with a high-caries level. Children from low-income households had the highest prevalence of dental caries. The Gini coefficient was 0.7 and the $\mathrm{SiC}$ Index 2.5. The percentage of caries prevalence was $39.3 \%$ (95\% CI: $35.8 \%-42.8 \%)$ and the mean for DMF-T was $0.9( \pm$ SD 1.5). Inequalities in the distribution of dental caries were observed and socioeconomic factors were found to be strong predictors of the prevalence of oral disease in children of this age group.
\end{abstract}

Descriptors: Public Health Dentistry; Epidemiology; Dental Caries; Socioeconomic Factors; Child.

\section{Introduction}

Socioeconomic gradients have been simultaneously associated with both caries experience and distribution among preschool and schoolchildren. ${ }^{1,2}$ Despite a global decline in dental caries experience in children, inequalities in oral health exist ${ }^{3}$ leading to a high prevalence of disease in some minorities. ${ }^{4,5}$

An impressive body of scientific evidence demonstrates the underlying influence of psychosocial, economic, environmental, and political determinants on general health inequalities. However, it is now widely acknowledged that a more comprehensive and detailed understanding of oral health inequalities is needed to enable public health agencies to take effective action against this fundamental health problem. ${ }^{6}$ Therefore, it is important to know the pattern of dental caries distribution among different population groups.

To investigate this problem, Bratthall proposed using the Significant Caries Index $(\mathrm{SiC})$ to identify individuals with the highest prevalence of 
caries in each population. The $\mathrm{SiC}$ index is the mean $\mathrm{DMF} / \mathrm{dmf}$ for the one-third of the study group with the highest caries score. ${ }^{7}$ In a recent Brazilian study using the $\mathrm{SiC}$ index, a high polarization in the distribution of dental caries in 12-year-old adolescents was observed. ${ }^{8}$ In that study, the DMF-T index was 2.45 , with an $\mathrm{SiC}$ index of 5.08 , and $30 \%$ of the adolescents were shown to be caries-free. It was observed that $70 \%$ of caries cases were concentrated among $34 \%$ of the adolescents.

Another important measurement of the inequality in caries distribution is the Gini coefficient. ${ }^{9}$ This coefficient is a well-documented index of inequality used mainly to assess income distribution. Authors have recently advocated its use to measure dental caries experience. ${ }^{4,10}$ For instance, this indicator documents that the majority of caries experience is increasingly confined to a smaller percentage of the Brazilian population. ${ }^{10}$

In the Brazilian context, only a few studies have been carried out that clarify the factors associated with caries polarization. ${ }^{1,4,11}$ Moreover, few studies have documented the inequality in caries distribution using both the $\mathrm{SiC}$ index and Gini coefficient in a representative sample of Brazilian children. Therefore, in this cross-sectional study we assessed the inequality in caries distribution and the association between socioeconomic indicators and caries experience in a representative sample of 12 -year-old schoolchildren in Brazil.

\section{Methods \\ Ethics}

The study protocol was approved by the Committee of Ethics in Research of the Federal University of Santa Maria, RS, Brazil.

\section{Sample}

A survey was performed to assess the oral health status of 12-year-old schoolchildren in the city of Santa Maria, RS, Brazil. In 2008, the city population was 263,403 inhabitants, with 3,180 children aged 12 years old enrolled in public schools, which corresponds to nearly $85 \%$ of all 12 -year-old schoolchildren in the city. Multistage sampling considered all public schools in Santa Maria as primary survey units; 20 out of 39 schools were randomly selected. A random sample of children (second survey units) was extracted from a list encompassing all students enrolled in the selected schools.

For the sample calculation to assess the prevalence of dental caries, we adopted a standard error of $5 \%$, a confidence interval level of $95 \%$, and an expected prevalence of $50 \%$. In addition, the design effect was estimated to be 1.4 and $10 \%$ was added for non-responses. The decision to use a prevalence of $50 \%$ was based on lack of information regarding the actual prevalence of the outcome in the city of Santa Maria. The minimum sample size to satisfy the study requirements was estimated at 530 children. The assessment of association between caries experience and socioeconomic covariates was estimated using the following parameters: $5 \%$ of standard error, $80 \%$ of power, $95 \%$ of confidence interval, design effect of $1.4,10 \%$ for non-response, ratio unexposed to exposed 2:1 (high/low income) and a prevalence ratio of at least 1.4 to be detected. The actual number of participants (792) was larger than the minimum required by these parameters (722).

\section{Data Collection}

Data collection included dental examinations of the children and questionnaires sent to parents. Six examiners and six interviewers participated in the study. They were previously trained and calibrated for data collection during 36 hours.

The dental examination used international criteria standardized by the World Health Organization for oral health surveys. ${ }^{12}$ Children were examined in a room with natural light, using CPI probes and plane dental mirrors. The clinical examination recorded the prevalence of dental caries.

Socioeconomic characteristics were provided by parents and guardians. Educational level compared fathers and mothers who had completed 8 years of formal education, which in Brazil corresponds to primary school, with parents who had less. Household income was measured relative to the Brazilian minimum wage, a standard for this type of assessment, which corresponded closely to 280 US dollars during the period of data gathering. 


\section{Data analysis}

Data analysis used the STATA 9.0 software (Stata Corporation, College Station, TX, USA). Three outcomes were used in this study: prevalence of dental caries (DMF-T $>0)$, mean caries experience (DMF-T), and prevalence of children taking part of the polarization group. The polarization group was determined considering a cut-off point of DMF-T of 2.00, which corresponded to the mean DMF-T of the one-third of the study group with the highest caries score. Poisson regression analyses taking into account the cluster sample were performed to assess the association between the predictor variables and the outcomes. In the analyses, we calculated the prevalence ratio (PR; 95\%CI) to assess the predictors of caries prevalence and polarization group, and the rate ratio $(\mathrm{RR} ; 95 \% \mathrm{CI})$ to assess the predictors of caries experience (DMF-T). Poisson regression has been described as an appropriate analytical resource to assess factors associated with both count and binary outcomes. A backward stepwise procedure was used to include or exclude explanatory variables in the fitting of models. Explanatory variables presenting a $P$ value $\leq 0.20$ in the assessment of correlation with each outcome (unadjusted analyses) were included in the fitting of models. Explanatory variables were selected for the final models only if they had a $P$ value $\leq 0.05$ after adjustment.

An online spreadsheet provided by the WHO Collaborating Centre in Malmö University, Sweden, ${ }^{13}$ was used for the SiC calculation. The assessment of Gini coefficients was calculated using a spreadsheet provided and published in another study. ${ }^{4}$ The Gini coefficient varies between 0 , which reflects the complete absence of inequality in the distribution of disease, and 1, with higher figures reflecting higher levels of inequality. Graphically, the coefficient is represented by the area between the line of equality and the Lorenz curve. ${ }^{14}$ The closer the coefficient is to 1 , the more unequal is the caries distribution.

\section{Results}

A total of 792 children, $44.3 \%$ boys and $55.7 \%$ girls, were recruited for the study. The response rate was $90 \%$ of all children invited. Non-participation was mainly due to children who were absent on the day of the examination, or who forgot to bring the consent form signed by their parents.

Figure 1 indicates the distribution of caries in the city of Santa Maria and shows the overall caries prevalence. The mean of decayed, missing, and filled teeth in the population was 0.9 .

Figure 2 provides information on the measurement of inequality in the distribution of dental disease, by displaying the Lorenz curve for the observed sample and average DMF-T. A high inequality in the distribution of dental caries was observed in this study. While the mean DMF-T was $0.9( \pm$ SD 1.5), the SiC index was 2.5 (Figure 1), and the Gini coefficient was 0.7 .

Prevalence of dental caries and dental caries experience with associated factors are shown in table 1. The prevalence of dental caries was $39.27 \%$ (311 children of 792). After the adjustment for confounders, only household income remained associated

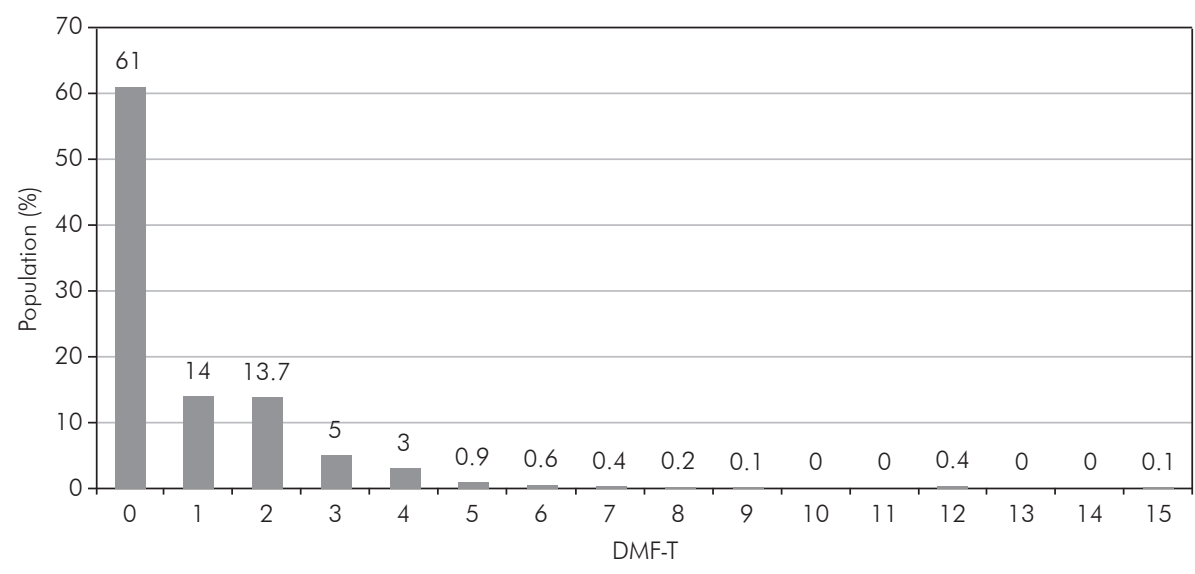

Figure 1 - Distribution of DMF-T in 12-year-old schoolchildren in Santa Maria, RS, Brazil: DMF-T index $=0.90$ (Mean of decayed, missing and filled teeth). 


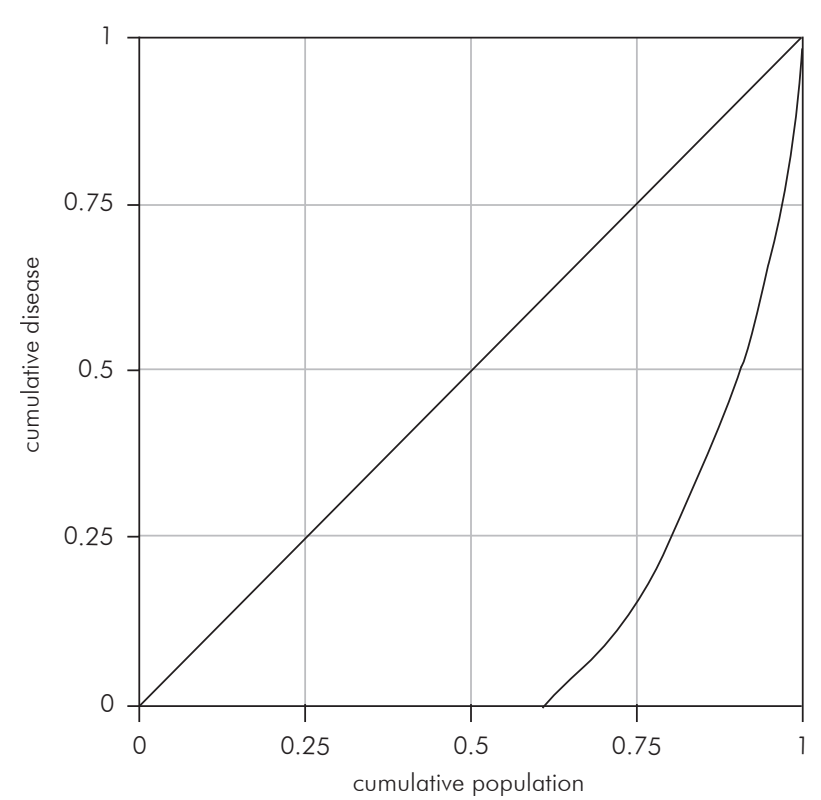

Figure 2 - Lorenz curve for the DMF-T distribution (12-yearold children) in Santa Maria, RS, Brazil: Gini coefficient = 0.7. with the outcome. Children from low-income households had both higher prevalence of dental caries and higher mean DMF-T than other children.

Table 2 shows the association of possible predictors and the prevalence of severe dental caries (polarization group - DMF-T > 2). Multivariate regression models showed household income as a possible predictor for individuals with severe dental caries.

\section{Discussion}

This study found a high inequality in the distribution of dental caries. Moreover, socioeconomically disadvantaged children had a higher prevalence of oral disease. In accordance with previous studies, this study emphasizes that despite a decline in caries experience in most countries during the last decades, a high prevalence of disease is observed in some minorities. ${ }^{8,15}$ However, patterns of caries dis-

Table 1 - Prevalence of dental caries (DMF-T > 0) and dental caries experience (DMF-T) with associated factors.

\begin{tabular}{|c|c|c|c|c|c|c|}
\hline \multirow{2}{*}{ Variables } & \multicolumn{3}{|c|}{ With dental caries (DMF-T > 0) } & \multicolumn{3}{|c|}{ DMF-T } \\
\hline & $\mathrm{N}(\%)$ & PR $(95 \% \mathrm{Cl})$ & $\mathrm{PR}_{\text {adj }}(95 \% \mathrm{Cl})$ & Mean $( \pm \mathrm{SD})$ & RR $(95 \% \mathrm{Cl})$ & $\mathrm{RR}_{\text {adj }}(95 \% \mathrm{Cl})$ \\
\hline Gender & $311(39.27)$ & & & & & \\
\hline Male & $128(36.47)$ & 1.00 & & $0.77(1.39)$ & 1.00 & \\
\hline Female & $183(41.50)$ & $1.13(0.95-1.35)$ & & $1.01(1.75)$ & $1.30(1.02-1.67)^{* *}$ & \\
\hline Skin Colour & $308(39.34)^{*}$ & & & & & \\
\hline White & $230(37.77)$ & 1.00 & & $0.84(1.58)$ & 1.00 & \\
\hline Non-White & $78(44.83)$ & $1.18(0.97-1.44)$ & & $1.06(1.60)$ & $1.25(0.95-1.63)$ & \\
\hline Income & $263(39.43)^{*}$ & & & & & \\
\hline$\geq 2$ Brazilian min. wage & 115 (33.72) & 1.00 & 1.00 & $0.70(1.33)$ & 1.00 & 1.00 \\
\hline$<2$ Brazilian min. wage & $148(45.40)$ & $1.34(1.11-1.62)^{* *}$ & $1.27(1.04-1.55)^{* *}$ & $1.14(1.83)$ & $1.63(1.25-2.13)^{* *}$ & $1.58(1.21-2.06)^{* *}$ \\
\hline Mother's schooling & $305(39.92)^{*}$ & & & & & \\
\hline$\geq 8$ years & $110(33.33)$ & 1.00 & 1.00 & $0.78(1.60)$ & 1.00 & \\
\hline$<8$ years & 195 (44.93) & $1.34(1.12-1.62)^{* *}$ & $1.22(0.99-1.50)$ & $1.01(1.58)$ & $1.29(0.99-1.68)$ & \\
\hline Father's schooling & $292(39.57)^{*}$ & & & & & \\
\hline$\geq 8$ years & $92(33.70)$ & 1.00 & & $0.71(1.39)$ & 1.00 & 1.00 \\
\hline$<8$ years & $200(43.01)$ & $1.27(1.04-1.55)^{* *}$ & & $1.04(1.75)$ & $1.44(1.09-1.91)^{* *}$ & $1.29(0.96-1.72)$ \\
\hline Mother's occupation & $305(39.00)^{*}$ & & & & & \\
\hline Employed & $180(36.22)$ & 1.00 & & $0.84(1.62)$ & 1.00 & \\
\hline Unemployed & $125(43.86)$ & $1.21(1.01-1.44)^{* *}$ & & $0.99(1.58)$ & $1.17(0.91-1.50)$ & \\
\hline Father's occupation & $294(39.41)^{*}$ & & & & & \\
\hline Employed & $258(39.63)$ & 1.00 & & $0.92(1.59)$ & 1.00 & \\
\hline Unemployed & $36(37.89)$ & $0.95(0.72-1.25)$ & & $0.73(1.20)$ & $0.79(0.56-1.13)$ & \\
\hline
\end{tabular}

*values lower than 792 due to missing data (unanswered questions in the questionnaire). ${ }^{* *} \mathrm{p}<0.05$. PR $(95 \% \mathrm{Cl})=$ Prevalence ratio $-95 \%$ Confidence interval; PR $_{\text {adi }}=$ Adjusted Prevalence Ratio; RR $(95 \% \mathrm{Cl})=$ Rate Ratio - 95\% Confidence Interval; RR $_{\text {adi }}=$ Adjusted Rate Ratio - 95\% Confidence Interval. 
Table 2 - Unadjusted and adjusted assessment of the association between the dependent variable "taking part of the polarization group" and associated factors.

\begin{tabular}{|c|c|c|c|c|c|}
\hline \multirow{2}{*}{ Variable } & \multicolumn{5}{|c|}{ Polarisation group (SiC Group) } \\
\hline & SiC Group N (\%) & PR (95\%Cl) & $P$ & $P R_{\text {adi. }}(95 \% \mathrm{Cl})$ & $P$ \\
\hline Gender & $87(11.27)$ & & & ** & ** \\
\hline Male & $32 \quad(9.12)$ & 1.00 & & & \\
\hline Female & $55(12.5)$ & $1.36(0.90-2.06)$ & 0.13 & & \\
\hline Skin Colour & $84(10.73)$ & & & ** & ** \\
\hline White & $60 \quad(9.85)$ & 1.00 & & & \\
\hline Non-White & $24(13.80)$ & $1.40(0.89-2.17)$ & 0.13 & & \\
\hline Income & $79(11.84)$ & & & & \\
\hline$\geq 2$ Brazilian min. wage & $26 \quad(7.62)$ & 1.00 & & 1.00 & \\
\hline$<2$ Brazilian min. wage & $53(16.26)$ & $2.13(1.36-3.32)$ & $<0.01$ & $2.02(1.29-2.18)$ & $<0.01$ \\
\hline Mother's schooling & $84(11.00)$ & & & $* *$ & \\
\hline$\geq 8$ years & $29 \quad(8.79)$ & 1.00 & & & \\
\hline$<8$ years & $55(12.67)$ & $1.44(0.94-2.20)$ & 0.09 & & \\
\hline Father's schooling & $83(11.25)$ & & & & \\
\hline$\geq 8$ years & 22 (8.06) & 1.00 & & 1.00 & \\
\hline$<8$ years & $61(13.12)$ & $1.62(1.02-2.58)$ & 0.04 & $1.36(0.83-2.21)$ & 0.83 \\
\hline Mother's occupation & $86(11.00)$ & & & ** & ** \\
\hline Employed & $52(10.46)$ & 1.00 & & & \\
\hline Unemployed & 34 (1 1.93) & $1.14(0.75-1.71)$ & 0.52 & & \\
\hline Father's occupation & $82(11.00)$ & & & & \\
\hline Employed & $75(11.52)$ & 1.00 & & & \\
\hline Unemployed & $7 \quad(7.37)$ & $0.63(0.30-1.34)$ & 0.23 & & \\
\hline
\end{tabular}

tribution and polarization have not been thoroughly investigated in 12-year-old children, especially using both the SiC index and Gini coefficient and considering their association with socioeconomic variables in a representative sample.

Notwithstanding the fact that the mean DMF-T of our study (Figure 1) was lower than that of Brazil (Mean DMF-T = 2.78), ${ }^{16}$ in general, we observed that deprivation gradients exist in caries experience and distribution. At lower levels of income, individuals had poorer oral health. The health differences across poverty-income groups were significant for all outcomes in the binary and adjusted analyses. Furthermore, an interesting discussion could be raised analyzing socioeconomic factors associated with children having no caries lesions. Further studies should be conducted to focus these associations.

Our results demonstrate that both caries experi- ence and prevalence were associated with household income. The strength of this association was more prominent for the polarization group, which means that children from low socioeconomic background were more likely to form part of the polarization group. Different mechanisms to explain income effects on health have been described. ${ }^{17,18}$ Individuals at lower socioeconomic levels may be at higher risk of diseases, through stress-induced ill-behavior and physiological effects of chronic stress. ${ }^{19}$ Recent research suggests that health may also be affected by the distribution of income within society. ${ }^{20,21} \mathrm{Al}-$ though we did not assess the potential multilevel effect of income distribution and individual income, the relationship between income and health at the individual level is a sufficient condition to produce health differences between populations.

Socioeconomic disparities in oral health ob- 
served in this study corroborate results from one recent study with preschool children in the same city. ${ }^{22}$ Income inequality, relative poverty, and social comparison have an impact on the individual's psychological well-being. ${ }^{23,24,25}$ These factors can affect health through psychosocial/stress pathways, which exert a direct effect on health and an indirect effect through health-related behaviors. ${ }^{20}$ The same observations have been made for oral health. ${ }^{26}$ Risk behaviors lie in the causal pathway between socioeconomic position and oral health and are more prevalent among socioeconomically disadvantaged groups. ${ }^{6}$ Therefore, a more comprehensive and detailed understanding of the underlying causes of oral health inequalities is needed to enable effective action to be taken in addressing this fundamental public health problem. ${ }^{6,27}$

In addition to documenting current levels of dental disease, this study also assessed the inequality of disease distribution among schoolchildren. We used the Gini coefficient ${ }^{9}$ and the $\mathrm{SiC}$ index ${ }^{7}$ to measure the disease distribution. The mean DMFT value alone does not represent the skewed distribution and may give the impression that the caries situation is under control, while in reality several individuals still have very high caries rates. ${ }^{7}$ A previous study demonstrated the utility of these indexes as interchangeable tools for measuring caries inequality

\section{References}

1. Pereira SM, Tagliaferro EP, Ambrosano GM, Cortelazzi KL, Meneghim M de C, Pereira AC. Dental caries in 12-yearold schoolchildren and its relationship with socioeconomic and behavioural variables. Oral Health Prev Dent. 2007 Nov;5(4):299-306.

2. Traebert J, Guimaraes L do A, Durante EZ, Serratine AC. Low maternal schooling and severity of dental caries in Brazilian preschool children. Oral Health Prev Dent. 2009 Mar;7(1):3945 .

3. Sabbah W, Tsakos G, Chandola T, Sheiham A, Watt RG. Social gradients in oral and general health. J Dent Res. 2007 Oct; $86(10): 992-6$.

4. Antunes JL, Narvai PC, Nugent ZJ. Measuring inequalities in the distribution of dental caries. Community Dent Oral Epidemiol. 2004 Feb;32(1):41-8. among Brazilians. ${ }^{4}$ In the present study, both indicators confirm the figures for high inequality in caries distribution, namely that the majority of caries occur to a relatively small number of children. These inequalities in oral health found in our study have been described regarding social inequalities. ${ }^{23}$ These observations explain the demand of public health agencies that attention be paid to those segments of the population with higher levels of dental needs.

This study involved 792 schoolchildren in a representative sample of 12-year-old children enrolled in public schools in the city. The authorities of one particular school did not allow examiners to collect data from its students. However, nearly $85 \%$ of the children in this age group were enrolled in public schools. Moreover, our study observed that children from all social classes are enrolled in public schools in Santa Maria. Therefore, we cautiously consider generalizations of our results for all 12-year-old children living in the city.

\section{Conclusion}

Socioeconomic factors are strong predictors of inequality in caries distribution in Brazilian schoolchildren. This is important from a public health perspective mainly for the identification of sections of the population that need to be more closely monitored for oral health.

5. Amaral MA, Nakama L, Conrado CA, Matsuo T. Dental caries in young male adults: prevalence, severity and associated factors. Braz Oral Res. 2005 Dec;19(4):249-55.

6. Sanders AE, Slade GD, Turrell G, John Spencer A, Marcenes W. The shape of the socioeconomic-oral health gradient: implications for theoretical explanations. Community Dent Oral Epidemiol. 2006 Aug;34(4):310-9.

7. Bratthall D. Introducing the Significant Caries Index together with a proposal for a new global oral health goal for 12-yearolds. Int Dent J. 2000 Dec;50(6):378-84.

8. Peres SH, de Carvalho FS, de Carvalho CP, Bastos JR, Lauris JR. [Polarization of dental caries in teen-agers in the southwest of the State of Sao Paulo, Brazil]. Cien Saude Colet. 2008;13 Suppl 22:2155-62. Portuguese.

9. Kawachi I, Kennedy BP. The relationship of income inequality to mortality: does the choice of indicator matter? Soc Sci Med. 1997 Oct;45(7):1121-7. 
10. Antunes JL, Jahn GM, de Camargo MA. Increasing inequalities in the distribution of dental caries in the Brazilian context in Finland. Community Dent Health. 2005 Jun;22(2):94-100.

11. Campus G, Solinas G, Maida C, Castiglia P. The 'Significant Caries Index' (SiC): a critical approach. Oral Health Prev Dent. 2003 Sep;1(3):171-8.

12. World Health Organization. Oral health surveys: basic methods, $4^{\text {th }}$ ed. Geneva: World Health Organization; 1997.

13. World Health Organization. WHO oral health country/area profile program [homepage at internet]. Malmö University, Sweden: WHO; [cited 2010 Apr 6]. Available from: http:// www.whocollab.od.mah.se/sicdata.html.

14. Creedy J. The dynamics of inequality and poverty: comparing income distributions. Cheltenham (UK); Northampton (MA, USA): E.Elgar 1998.

15. Antunes JL, Frazao P, Narvai PC, Bispo CM, Pegoretti T. Spatial analysis to identify differentials in dental needs by area-based measures. Community Dent Oral Epidemiol. 2002 Apr;30(2):133-42.

16. Brasil. Ministério da Saúde. Secretaria de Atenção à Saúde. Departamento de Atenção Básica. Coordenação Nacional de Saúde Bucal. Projeto SB Brasil 2003—Condições de saúde bucal da população brasileira 2002-2003: resultados principais. Brasília: MS-CNSB; 2004.

17. Kawachi I, Kennedy BP. Income inequality and health: pathways and mechanisms. Health Serv Res. 1999 Apr;34:215-27.

18. Lynch JW, Smith GD, Kaplan GA, House JS. Income inequality and mortality: importance to health of individual income, psychosocial environment, or material conditions. BMJ. 2000 Apr 29;320(7243):1200-4.
19. Wilkinson RG. Socioeconomic determinants of health. Health inequalities: relative or absolute material standards? BMJ. 1997 Feb 22;314(7080):591-5.

20. Bernabe E, Sheiham A, Sabbah W. Income, income inequality, dental caries and dental care levels: an ecological study in rich countries. Caries Res. 2009;43(4):294-301.

21. Celeste RK, Nadanovsky P, Ponce de Leon A, Fritzell J. The individual and contextual pathways between oral health and income inequality in Brazilian adolescents and adults. Soc Sci Med. 2009 Nov;69(10):1468-75.

22. Piovesan C, Mendes FM, Ferreira FV, Guedes RS, Ardenghi TM. Socioeconomic inequalities in the distribution of dental caries in Brazilian preschool children. J Public Health Dent. 2010 Aug 23; [Epub ahead of print]. DOI: 10.1111/j.17527325.2010.00191.x

23. Pattussi MP, Marcenes W, Croucher R, Sheiham A. Social deprivation, income inequality, social cohesion and dental caries in Brazilian school children. Soc Sci Med. 2001 Oct;53(7):915-25.

24. Wilkinson RG, Pickett KE. The problems of relative deprivation: why some societies do better than other. Soc Sci Med. 2007 Nov;65(9):1965-78.

25. Wilkinson RG, Pickett KE. Income inequality and socioeconomic gradients in mortality. Am J Public Health. 2008 Apr;98(4):699-704.

26. Downer MC, Drugan CS, Blinkhorn AS. Correlates of dental caries in 12-year-old children in Europe: a cross-sectional analysis. Community Dent Health. 2008 Jun;25(2):70-8.

27. Newton JT, Bower EJ. The social determinants of oral health: new approaches to conceptualizing and researching complex causal networks. Community Dent Oral Epidemiol. 2005 Feb;33(1):25-34. 